2

Public Service Broadcasting Structure and Performance in Morocco and the MENA Region 



\title{
Public Service Broadcasting Structure and Performance in Morocco and the MENA Region
}

\author{
Bouziane Zaid \\ Al Akhwayn University in Ifrane, Morocco
}

\begin{abstract}
As in the Middle East and North African (MENA) region, public service broadcasting (PSB) in Morocco suffers from the existence of authoritarian forms of governance that hinders PSB performance. Technology is also a factor. TV and radio stations still rely on analog terrestrial and digital satellite broadcasting and their online presence are extensions of their analog versions, rather than new digital multiplatform distribution systems. In Morocco, the wave of political liberalization and democratization that marked the second half of the 1990s resulted in major media reforms especially in the broadcasting sector. The High Authority for Audiovisual Communication was created in 2002 as an independent public institution to establish the legal framework for the liberalization of the audiovisual sector and to oversee the PSB sector in the country. The paper analyzes the legal environment to assess the extent to which PSB is safeguarded from political influence. The study found that the overall non-democratic cultures within Morocco and the countries of the MENA region are the main determinants of performance. In some MENA countries, the legal framework and the institutional structure were created to provide the conditions for public service to materialize. PSB performance in this region remains weak, however. The study argues that unless there is political will at the highest level, a public service system will be nothing more than a pseudo 'public' system bouncing back and forth between milder and stronger forms of authoritarianism.
\end{abstract}

Keywords: Public service broadcasting, Morocco, MENA region, competitive authoritarianism, broadcasting law and regulation, media reform

Bouziane Zaid, P. O. Box 1724, Avenue Hassane II, Ifrane, Morocco 53000.

Email: b.zaid@aui.ma

Copyright (C) 2016 (Bouziane Zaid)

A. Rahman \& G. F. Lowe (Eds.), Public Service Media Initiatives in the Global South

(c) $(1)(-)$ Licensed under the Creative Commons Attribution-NonCommercial-NoDerivatives 4.0

Available at http://monographs.lib.sfu.ca

DOI: $10.21810 /$ sfulibrary.1.8 



\title{
Public Service Broadcasting Structure and Performance in Morocco and the MENA Region
}

\author{
Bouziane Zaid \\ Al Akhwayn University in Ifrane, Morocco
}

\section{History and Background}

With the exception of post Arab Spring Tunisia, the Middle East and North African region is characterized by the predominance of authoritarian regimes. International organizations such as Freedom House and Reporters without Borders consider this region's media systems as the least free in the world. Freedom House ranks Tunisia and Israel as free, Morocco, Kuwait, and Lebanon as "partly free," and ranks the rest of the countries as "not free." 1 In January 2014, the Tunisian Constituent Assembly voted a democratic constitution that affirms the people's sovereignty and the country's attachment to the principles of separation of powers. Article 127 of the Constitution establishes HAICA as the regulatory body for audiovisual communication and assign it the role of ensuring independence, diversity and pluralism in the sector. Given the novelty of these initiatives, the results are still to be seen. For the rest of the MENA region, broadcasting continues to be under government control where state officials dictate media policy and interfere with editorial decisions. In Lebanon, Morocco, Jordan, and Bahrain, there is a mix of state and private ownership. In the rest of the MENA region, broadcasting systems are owned by the states (Rugh, 2004).

The history of the Moroccan broadcasting system has many similitudes with the history of broadcasting in the MENA region. Morocco, a protectorate of France from 1912 to 1956, inherited a media system built by the French who used radio and television as instruments of colonial rule (Zaid, 2010). The French handed them over to the newly independent government instead of private owners, because of their experiences at home with state owned broadcast media (Rugh, 2004). Like many countries in the post-colonial era, Morocco perceived the role of media to be in the service of nation building (Mowlana, 1985). Nation building is also a central rationale for government interference in media, also in mature democratic countries. Nation building provided justification for media regulation, and for the legitimacy of PSB in Western Europe. However, the newly independent post-colonial countries considered normative principles such as social responsibility and media in the service of public interest as secondary to a more essential national building project. The political and historical contexts of these countries during the Cold War era was characterized by competing ideologies vying for political power and public support. To ensure political stability, these states argued that they had to control the flow of information in their countries to maintain public order by controlling the public sphere. Because of the Cold War, Western countries were more concerned about East/West alliances than requiring these countries to meet their commitments of the protection of human rights (Thussu, 2004).

${ }^{1}$ Freedom House, Middle East and North Africa, retrieved from, https://freedomhouse.org/regions/middle-east-and-north-africa, (accessed 29 February 2016). 
Until the mid-1990s, and much like the rest of the MENA region, the culture of media in Morocco was authoritarian, administrative and partisan (Zaid \& Ibahine, 2011). The Moroccan state controlled the financing, regulation, production, and distribution of broadcast media, which are considered the most powerful media. Print media were much more developed with a dozen publications issued by various political parties. Opposition leaders used the print media as chief weapons of expressing dissent and for political agitation because they had no alternative for articulating their challenges against the regime.

The relationship between the regime and mass media took a radically different turn when the opposition and Socialist-led government was elected in 1997. The new government's mission was to enact political reforms aimed at promoting human rights, civil liberties, an open and a pluralist media, and establishing the rule of law. The wave of political liberalization and democratization that marked the second half of the 1990s resulted in major media reforms especially in the broadcasting sector. The High Authority for Audiovisual Communication (Haut Autorité de la Communication Audiovisuelle, HACA) was created in 2002 as a public institution to establish the legal framework for the liberalization of the audiovisual sector and to oversee public service broadcasting (PSB) in the country. In January 2005, the Moroccan parliament adopted the Audio Visual Communication Law, which put an end to the state's monopoly in broadcasting management. As a result of these initiatives, the structure of broadcast media was re-defined, a regulator was set up, public sector broadcasting was reformed, and a framework for private broadcasting was created.

Today, television and radio are the most influential media platforms in Morocco and represent the most important sources for news and information. This is due to low cost, the ability of TV and radio to supersede illiteracy, and universal access. Thus, television is the dominant media platform, accounting for 60 percent of total advertising expenditure; with 2M taking the lion's share of the TV ad spend (Oxford Business Group, 2013). Finally, according to Marocmétrie, the official Moroccan audience ratings firm, TV channels had a combined audience share in February 2013 of 40.4 percent, with 22.0 percent for $2 \mathrm{M}$ and 18.4 percent for $\mathrm{Al} \mathrm{Oula.}{ }^{2}$ However, for high-quality international and global news, educated and urban Moroccans turn to quality content channels, including Al Jazeera and other Arab satellite channels, and European global media players such as the BBC.

Internet access in Morocco has increased steadily in recent years, although obstacles remain in parts of the country. But internet penetration grew from just over 21 percent of the population in 2007 to 55 percent in 2013, according to the International Telecommunication Union (ITU) (2013). By end of 2013, more than 2 in every 100 inhabitants possessed a fixedbroadband subscription, or around 14 percent of all subscribers. ${ }^{3}$ Internet use among Moroccans is characterized by an interest in social media and user-generated content, as well as domestic news portals.

2 Numbers presented by Younes Alami, director of Marocmetrie at the conference on "Data collection on television and on-demand audiovisual services in the countries of the partnership of the Euromed Audiovisual III programme," organized by the European Audiovisual Observatory and the Arab States Broadcasting Union (ASBU), in the ASBU headquarters in Tunis, September 23-24, 2013.

3 “Fixed (wired-) broadband subscriptions," ITU, 2000-2012, retrieved from, http://www.itu.int/en/ITU-D/Statistics/Pages/stat/default.aspx 
One of the structural problems in Moroccan print media is the low rate of newspaper and magazine primary circulation and pass-along secondary readership. But newspaper circulation is miniscule at 300,000 daily; less than 1 percent of the population.

The Audiovisual Communication Law assigns public service obligations to Morocco's stateadministered TV and radio stations. ${ }^{4}$ There are no specific public service obligations for commercial media, but the sector must abide by the general philosophy and recommendations in the 2005 audiovisual law. The preamble of the Law states that the general philosophy is founded on the Kingdom's constitutional principles of Islam, monarchy, and national unity. It also states that programs must appeal to all regions of the country and must respond to the audiences' needs. Broadcasters must provide an objective and balanced coverage of news events, while not taking sides with any political party, ideology or doctrine. They must promote Moroccan arts and culture and encourage local production. All broadcasting companies must preserve neutrality and not serve the interests of a political party, an ideology, an ethnicity, or particular economic or financial interests.

With the exception of Jordan, Tunisia and Lebanon, which have created broadcasting regulatory bodies, the rest of the MENA region continues to exert direct state control over broadcasting. But the mission of PSB is at an embryonic stage in Morocco, Jordan, Tunisia and Lebanon. While the legal framework and institutional structure provide the conditions for a public service practice to materialize, they do not guarantee its performance, given the nature of the political systems in these countries (Sakr, 2012).

This study adopts a multi-method approach that combines document analysis and qualitative in-depth interviews with HACA personnel in the Monitoring department, which is in charge of monitoring the contents of radio and TV stations to make sure they are in compliance with the laws and regulations stipulated in the audio-visual communication law, and with the provisions in their licensing obligations documents (LODs) that include public service mandates. The sample criterion was purposive (Patton, 2002) because the interviewees were selected on the basis of their expertise, and on their willingness to speak openly in private. ${ }^{5}$

${ }^{4}$ The TV stations are Al Oula, 2M and Medi 1 TV. The list of SNRT radio stations: Idaa Wataniya (general interest station in Arabic), Chaine Inter (general interest station in French), Idaa Al Amazighiya (Amazigh language and culture station), Mohamed VI du Saint Qoran (religious channel), and Regional radio stations (Agadir, Agadir, Casablanca, Dakhla, Fes, Laâyoune, Marrakech, Meknes, Oujda, Tanger, Tétouan, Rabat, El Hoceima and Ouarzazate).

5 The interviews lasted from one hour to one hour and fifteen minutes. All interviews took place between October and December 2013. I interviewed fourteen employees from HACA. They all work in the Monitoring department. Four are managers in various services and ten are mid-level employees. I had the opportunity to conduct two intensive training sessions over two weekends in October and December 2013 for the monitoring department personnel on content analysis. I had 20 trainees and I managed to get to know them and what they do. When I approached the interviewees, I promised them confidentiality so that they are comfortable discussing HACA's monitoring of content. As a result, all the interviewees insisted to stay anonymous for fear of losing their jobs.

Although semi-structured interviews as a methodology do not lead to generalizable results, the quality of the information provided by the interviewees given their expertise in the subject matter and their proximity to decision making on media content within HACA renders the findings of very general importance. How HACA interferes with content is at the core of the boundary crossing from state control to public service, and these interviews provide solid evidence to illustrate that. 


\section{Organization and Structure of PSB}

HACA was established August 31, 2002 as an administrative body in charge of regulating the audio-visual communication sector. HACA is the Higher Council of the Audio-Visual Communication, a nine-member council with three major missions. First, it provides advice for the King, the Prime minister and government, and both chambers of the Parliament on issues related to audio-visual sector. Second, it authorizes the creation of audio-visual companies, and grants licenses and the use of radio frequencies. Finally, it monitors compliance with the laws and regulations applicable to the audio-visual sector, as well as pluralism (in particular in the matter of political parties access), and compliance to advertising regulations. HACA also consists of the General Directorate of Audio-Visual Communication (Direction Général de la Communication Audiovisuelle-- DGCA), which is run by the HACA's Director General and represents administrative and technical services. The DGCA includes research and development, program monitoring, technical infrastructure, and the legal department.

HACA receives many bids from private individuals or companies seeking new licenses and oversees compliance for TV and radio stations with their Licensing Obligation documents (called Cahier des Charges). The Cahier des Charges constitutes a written agreement between the HACA and broadcast media outlet and the HACA, and through its mechanism of monitoring and surveillance makes sure the media outlets comply with their obligations.

Two years after the creation of HACA, the Moroccan parliament adopted the Audiovisual Communication Law in January 2005, which put an end to the state's monopoly in broadcast management. This is the law that regulates radio and television in Morocco. Like most broadcasting policies around the world, broadcasting is supposed to be accountable to the public and must promote democratic ideals, should enhance national audio-visual communication production, and preserve the national cultural heritage. The most positive development introduced by this law is the establishment of the legal framework for private ownership. Before this law audiovisual communication in Morocco functioned in a legal void. The existing radio and TV stations could only be created via a Royal decree, which meant one had to convince the King himself to approve a request for a license.

The Audiovisual Communication law carries the same restrictions of freedom of expression that the Press Code ${ }^{6}$. Article 9 states that TV and radio programs must not question Morocco's dogma, Islam, monarchy, and Western Sahara. ${ }^{7}$ The law does not stipulate jail sentences, but that is not needed because the Press Code does. Regarding ownership, Article 21 stipulates that any broadcasting company or shareholder can own or control another broadcasting company as long as he/she/it does not exceed 30 percent of the shares of the other company. This is intended to prevent any individual or company from controlling more than one media outlet. Only the Moroccan state can do that.

${ }^{6}$ The Press Code is the law that regulates print media in Morocco. It is called a "code" but in fact it is a law that contains provisions to imprison journalists. Although meant primarily for print media, the Press Code applies to broadcasting and the internet because Article 38 stipulates that the law applies to all forms of communication, whether written, printed, audiovisual, or electronic.

7 The Western Sahara refers to the southern province in Morocco. The legal status of the territory and the question of its sovereignty remain unresolved; the territory is contested between Morocco, Algeria and the Polisario. 
In April 2005, three years after the creation of HACA, Moroccan Radio and Television (Radiodiffusion et Television Marocaine), the institution that managed state TV and radio, was transformed from a subsidiary of the Ministry of Communication to the National Company of Radio and Television (la Société Nationale de Radiodiffusion et de TélévisionSNRT). The SNRT is a public company, self-proclaimed as independent, that manages public service radio and TV stations, and is no longer subject to the financial control and supervision of the Ministry of Communication. It is the largest broadcasting company and controls the nine formerly state-owned television stations and six radio stations. ${ }^{8}$

The Law assigned public service obligations to Al Oula, ${ }^{9} 2 \mathrm{M},{ }^{10}$ and Medi $1 \mathrm{TV},{ }^{11}$ the three nationwide public service TV stations, and to the SNRT radio stations. In May 2014, Medi 1 TV became private and HACA issued a new Cahier des charges (licensing obligations document) which no longer defines the station as a public service broadcaster but as a "general television service for news, knowledge and culture."12 Medi 1 TV must abide by the general philosophy and recommendations in the 2005 audiovisual law.

In terms of funding, PSB television and radio stations receive public funding via a tax added to the electricity bills that every Moroccan household and business pays. ${ }^{13}$ This state subsidy is meant to allow the public broadcasters to compete with satellite TV and private radio. The two public service TV stations Al Oula and $2 \mathrm{M}$ also rely on advertising as a main source of income. One of the cornerstones of PSB ethics (and media more broadly) is the independence of editorial content from advertisers' influence. Although there is no indication that the SNRT and 2M stations bias their contents to benefit advertisers, the fact that they receive advertising money presents potential conflicts of interest with their public service functions.

${ }^{8}$ List of SNRT Stations: for TV, Al-Aoula (general channel), Arriadia (an all sports channel), Arrabiaa (education and cultural channel), Al Maghribia (channel for the Moroccan community abroad), Assadissa (religious channel), Laayoune (regional TV of the Southern region), Assabiaa (fiction, films and TV series channel), Amazighiya (Amazigh channel). For Radio: Idaa Wataniya (general interest station in Arabic), Chaine Inter (general interest station in French), Idaa Al Amazighiya (Amazigh language and culture station), Mohamed VI du Saint Coran (religious channel), and Regional radio stations (Agadir, Agadir, Casablanca, Dakhla, Fes, Laâyoune, Marrakech, Meknes, Oujda, Tanger, Tétouan, Rabat, El Hoceima and Ouarzazate).

9 Launched on March 3 1962, Al Oula (formerly known as RTM) was the only television station available for Moroccans until 1989 when 2M was launched. It was state-owned and controlled.

102M started off in March of 1989 as a private TV station, and due to financial hardships, the state bought 72 percent of its shares in January 1996. Today it is state-owned.

${ }^{11}$ Created in 2005, Medi 1 was initially owned by the state. Its radio affiliate was launched in 1981 as part of a Moroccan-French partnership comprising associates from banks and major enterprises of the two countries. Medi 1 TV, the third national public channel, turned private when two Emirate investment groups (Nekst Investments and Steeds Medias) bought 54 percent of its shares. HACA granted Medi 1 TV a license for private broadcasting in May 2014. See Cahier des Charges Medi 1 TV (document detailing the legally binding licensing conditions), retrieved from http://haca.ma/CC/Medi1TV.pdf, (accessed on 12 August 2015).

12 See Cahier des Charges Medi 1 TV (document detailing the legally binding licensing conditions), retrieved from, http://haca.ma/CC/MedilTV.pdf (accessed on 12 August 2015).

${ }^{13}$ Media Sustainability Index. Retrieved from

http://www.irex.org/sites/default/files/u115/Morocco\%202012\%20MSI.pdf (accessed 20 January 2015). 


\section{Transition from PSB to PSM}

The digital switchover in the MENA region was set for 2015. ${ }^{14}$ According to the ITU, digital terrestrial broadcasting service is available in Morocco, Tunisia, Saudi Arabia, Iraq, Mauritania, and Sudan. It is planned in Algeria, Bahrain, Egypt, Jordan, Oman, Syria, and the UAE. The service is unavailable in Kuwait, Lebanon, Libya, Palestinian Authority, Qatar, and Yemen. The Moroccan national broadcaster SNRT carried out the digital switchover in 2015. Morocco has witnessed the development of new platforms and avenues to communicate public service broadcast content in digital format. In March 2007, the Ministry of Communication introduced DTT - Digital Terrestrial Television (Television Numerique Terrestre, TNT) to transmit the state-administered TV stations in a digital format.

The DTT service allows audiences to watch all the state-administered televisions stations and is meant on the one hand to package the Moroccan channels for households without access to satellite TV, and on the other hand to offer an alternative for households with access to satellite TV. An even less significant digital platform (in terms of audience share) is TV via ADSL, a digital TV service provided by Maroc Telecom. Only Moroccans with access to fixedbroadband internet subscription can take advantage of this service.

Current debates on broadcasting focus on the impact of the configuration of new digital and multiplatform distribution systems on traditional broadcasting structures, business models, and reception patterns (Lowe, Jauert, \& Bardoel, 2008; Lowe, Jauert, \& Steemers, 2012). They also focus on the difficult conditions and uncertain future of PSB including growing political hostility, increased competition for revenues, and the progressive fragmentation of audiences. In Morocco, radio and television are still distinct media with a life of their own. Due to low literacy levels and lack of access to online media, broadcasting companies have not yet crossed the boundaries of their own media and transformed themselves into crossmedia organizations with new digital multiplatform distribution systems. The main PSB TV stations receive funding from the state and revenue from advertising, they rely on digital satellite broadcasting, and their online presence are extensions of their analog versions, rather than new distribution systems. As the next section will show, in Morocco political control represents the main constraint for PSB.

\section{Critical Issues of Public Service Media}

An initial examination of the legal framework and the institutional structure that the Moroccan state set up shows that the media reforms illustrate a deeply conflicted orientation. On the one hand, the reforms sought to relieve broadcasting from political control by turning the state broadcasting system into public service system. On the other hand, the state established a system that limits that realization for fears that the results could destabilize the status quo. The state controls media content directly through repressive laws and through a regulatory institution that lacks independence. The conflicted orientation is

${ }^{14}$ ITU, Switching from analogue to digital television. Retrieved from https://itunews.itu.int/en/2346-Switching-from-analogue-to-digital-television.note.aspx (accessed 29 February 2016). 
the result of the nature of Morocco's political regime which is a competitive authoritarian regime, not a transitional democracy. Levitsky and Way (2002) introduced this framework into the comparative study of authoritarianism where they challenged the "democracy bias" embedded in much of the literature on the post-Cold War regimes. When seen through the lens of democratization, hybrid regimes were categorized as flawed, incomplete, or 'transitional' democracies." Various terms were used to describe these transitional democracies such as "evolving democracy," "nascent democracy," "ongoing democracy," and "would be democracies." Levitsky and Way argue that these characterizations are misleading. They propose, in line with scholars such as Guillermo O'Donnell (1996) and Thomas Carothers (2002), to stop treating these regimes as transitional but to conceptualize and theorize them for that they are, as distinct and non-democratic regime types.

Competitive authoritarian regimes utilize elements of democracy to ensure domination over the other opposition forces in the country. Levitsky and Way (2002) define competitive authoritarianism as civilian regimes in which "formal democratic institutions are widely viewed as the primary means of gaining power, but in which fraud, civil liberties violations, and abuse of state and media resources so skew the playing field that the regime cannot be labeled democratic" (p. 4). These regimes are competitive in the sense that the democratic institutions are real and that "opposition forces can use legal channels to seriously contest for (and occasionally win) power; but they are authoritarian in that opposition forces are handicapped by a highly uneven-and even dangerous-playing field. Competition is thus real but unfair" (p. 4). Competitive authoritarian regimes are characterized by the presence of some democratic institutions and some democratic practices such as elections, multi-party system, and in our case, self-proclaimed independent media regulator within the authoritarian state. Morocco's media reforms are in line with this vision of governance whereby the state creates democratic institutions to use them as a site of struggle with opposition forces while maintaining control through establishing an uneven playing field.

The media represent an important site of contestation. In competitive authoritarian regimes, both private and public media system exist. Political parties and opposition groups have access to print and online media, and in today's digital world, bloggers and internet users can serve as watchdogs and may act as a Fourth Estate in monitoring political abuses. Authoritarian regimes, however, try to limit the exposure of citizens to alternative information and views by placing "restrictions on means of communication, media content and media consumption" (Schedler, 2009). They have at their disposal an array of choices in terms of how they can strategically contain the flow of information, from repressive laws and restrictive broadcasting regulations, to blocking and filtering internet content, and imprisoning journalists. The state established a 'PSB' system it can control through regulatory structures that allows it to tilt the playing field to its favor. A look at the media law and the regulatory institution shows some of the mechanisms the state uses to maintain an uneven playing field. The PS broadcasting could as readily mean Political Service instead of public service.

The Audiovisual Communication law carries restrictions on freedom of expression and therefore allows the state to interfere with content. Article 9, as noted earlier, is clear about this. A close look at HACA sheds doubt on its self-proclaimed independence from 
government, as illustrated in how the members are selected, i.e. seven of the nine members are appointed by the King and the prime minister.

It is clear that the state holds all the power within HACA's highest decision making apparatus. This law and the regulatory institution are sites of conflicted orientations. On the one hand, they open the door for more pluralism and diversity in media, while at the same time empowering state regulatory institution to make decisions on content that interferes with editorial independence. As a competitive authoritarian regime, the regime utilizes democratic institutions to simultaneously reform its media system and to entrench these institutions within authoritarian laws. The result is the maintenance of the status quo while giving the impression that a democratization process is in progress.

With regards to content, the old practices of using broadcasting as an integrated component of the mechanisms for repression and control remain in place. The news output of the two PSB stations did not change with the liberalization of the audiovisual sector, and HACA interferes with private radio stations that attempt to provide a venue for open political discussions, disabling editorial independence and squashing such initiatives. For many of the interviewees, ${ }^{15}$ the "holiness" of Royal activities and the amount of air time they occupy on public service channels is a clear violation of their public service mandate. "We are incapable of flagging such things, we risk losing our jobs," says one of the interviewees who has worked at HACA since its creation in 2002.

HACA displays more potency when it monitors political discussions on private radio stations. In May 2010, the Monitoring department flagged a statement made during an interview of a film producer in a talk show in Radio Mars, a non-political sports and music radio station. When asked about his dream job, the film producer responded saying that he would like to be the first Moroccan president if Morocco were ever to be a republic. Immediately, HACA ordered the station off the air for 48 hours (from Thursday 3 June to Saturday 5 June), levied a fine of 57,000 MAD (6500 USD), and demanded the station make a public apology for the statement. One interviewee said this was unexpected by his superiors because it is an entertainment radio station, and "the interview was casual; there was nothing political about it." He had to signal the statement because instructions from the Monitoring department are clear: they must signal any statement made on radio or television that question the monarchy in any way. To utter a phrase on the airwaves that associates the identity of Morocco with a republic is considered extremely dangerous, the interviewee said.

Besides, the oppressive nature of the media laws, the language is vague and allows a wide margin of interpretation. Words and phrases such as "prejudice" or "offense" can be interpreted in many ways. It is difficult to interpret Article 9 of the Audiovisual Communication law, which states that radio and TV contents must not "harm or defame" (porter prejudice) the country's dogmas (the Monarchy, territorial integrity and Islam). It is hard to determine if a statement represents harm or is defamatory in any sense.

15 Interviews conducted with fourteen employees from HACA. They all work in the Monitoring department. Four are managers in various services and ten are mid-level employees. 


\section{Assessment and Recommendations}

A healthy democracy depends on the quality of news and on the existence of a culture of dissent and debate. PSB must give citizens access to information and provide them with a platform where they can discuss ideas and form public opinion. In the MENA region, most countries do not yet have a structure in place for this to materialize, and thus rules out genuine public service broadcasting. The state continues to own and control TV and radio contents and uses the media as part of their apparatus of political repression and control. In countries where structures are in place in the form of regulatory institutions, public TV and radio institutions, and laws, PSB systems have the potential to be an adequate structure for ensuring an efficient public service media provision. However, the existing political systems do not provide the conditions that are necessary to facilitate a democratizing environment where PSB could materialize. Morocco provides a poignant example that illustrates.

The broadcasting system in Morocco can be seen as promising in the sense that the state laid out a structure that, if truly implemented, has the potential to ensure an efficient democratic public service media system. However, the old practices of using broadcasting as an integrated component of repression and control hinder this. The news output of the PSB stations did not change with the liberalization of the audiovisual sector. And when private radio stations attempt to provide a venue for open political discussions, HACA interferes to squash such initiatives. In the international history of PSB, some state control has been necessary to manage broadcasting also in democratic countries, but it has not extended to control over content and editorial independence. Licensing radio and TV stations was bound by obligations to provide public service (Christians, Glasser, McQuail, Nordenstreng, \& White, 2009). Therefore, the question is not whether the state wields power in the management of broadcasting, but rather what kinds and how much. In democratic countries, the state exercises authority over licensing, policy and regulations, and usually the appointment of executive managers in the broadcasting stations and the regulatory agency, but not over content (with the exception of indecent content such as violence, prurient nudity, racism, hate speech, etc.).

In Morocco, the locus of power in broadcasting goes beyond licensing and policies to directly impact editorial decisions. The state did not hand over power to media institutions to do their job of informing and educating the citizenry. Instead, it maintained control over the media landscape through a series of restrictive laws that allow it to interfere with editorial independence of media organizations.

Moroccan PSB provides historical evidence that there is no real political will to liberalize and democratize the country as a whole. Thus, the legal framework and the institutional structure provide the conditions for public service to materialize, but they do not guarantee performance. The overall non-democratic culture within the country is arguably the main determinant and obstacle to progress. From a political economy perspective, any study of PSB in non-democratic countries should examine the nature of the political regime to get a clear sense of where the locus of power is and how much the state yields (and wields) in its management of broadcasting. 
As a competitive authoritarian regime, the Moroccan state utilizes democratic institutions to reform its media system while entrenching these institutions within authoritarian laws. The result is the maintenance of the status quo while giving the impression that democratization process is in progress. As such, unless there is political will at the highest level of the political pyramid, public service system will be nothing more than a pseudo system bouncing back and forth between milder and stronger forms of authoritarianism.

\section{Recommendations}

1. The appointment process in HACA's Higher Council and the criteria for nomination should be more transparent and should be open to public debate. There are important stakeholders that are not represented in the council including media professionals, unions, courts, civil society, and consumer groups.

2. National media laws must comply with Article 19 of the International Covenant on Civil and Political Rights (ICCPR) which Morocco signed and ratified on 3 May 1979. An examination of the existing laws (the Broadcast Law, the Press Code, and the Penal Code) indicates the weakness of these rights. The restrictions in the existing laws go beyond those expressed in Article 19 such as "respect of the rights or reputation of others" and "the protection of national security or of public order, or of public health or morals.”

3. The language in the laws must be more precise. Terms such as "offense" or "public order" are vague and the authorities retain the right to define and interpret such vague terms as they please, thus opening the door for abuse.

4. The laws must not give the state the right to interfere with editorial independence of PSB.

5. As history shows, the most powerful guarantees for political stability are democratic forums of governance and respect for basic human rights. In a world where information is available to citizens, the MENA region states can no longer use broadcasting as an instrument for propaganda and political control.

\section{Acknowledgment}

This article contains contents that have been published in the chapter entitled "State-administered public service broadcasting in Morocco" in the book, Public Service Media Across Boundaries, edited by Greg Lowe and Nobuto Yamamotu and published by Nordicom in Göteborg, Sweden. 


\section{References}

Carothers, T. (2002). The end of the transition paradigm. Journal of Democracy, 13(1), 5-21.

Christians, C., Glasser, T., McQuail, D., Nordenstreng, K., \& White, R. (2009). Normative theories of the media journalism in democratic societies. Urbana, IL: University of Illinois Press.

Haute Autorité de la Communication Audiovisuelle (2005). Loi Relative à la Communication Audiovisuelle. Retrieved from http://www.haca.ma/pdf/commaudiovisuelle.pdf

Haute Autorité de la Communication Audiovisuelle (2009). Rapport sur l'Attribution de Nouvelles Licences. Retrieved from http://www.haca.ma/pdf/Rapport\%20G2\%20MEP.pdf

International Telecommunication Union. (2013). Measuring the information society 2013. Retrieved from http://www.itu.int/en/ITU-D/Statistics/Pages/publications/mis2013.aspx

Levitsky, S., \& Way, L. (2002). Elections without democracy: The rise of competitive authoritarianism. Journal of Democracy, 13(2), pp. 51-65.

Levitsky, S., \& Way, L. (2010). Competitive authoritarianism. Hybrid regimes after the Cold War. Cambridge: Cambridge University Press.

Lowe, G. F. (Ed.) (2010). The public in public service media: RIPE@2009. Göteborg: Nordicom.

Lowe, G. F., Jauert, P., \& Bardoel, J. (Eds.). (2008). From public service broadcasting to public service media: RIPE@2007. Göteborg: Nordicom.

Lowe, G. F., Jauert, P., \& Steemers, J. (Eds.). (2012). Regaining the initiative for public service media: RIPE@2011. Göteborg: Nordicom.

Mowlana, H. (1985). International flow of information: A global report and analysis. Paris: UNESCO.

O'Donnell, G. A. (1996). Illusions about consolidation. Journal of Democracy, 7(2), 34-51.

Oxford Business Group (2013). The report: Morocco 2013. Retrieved from http://www.oxfordbusinessgroup.com/morocco-2013

Patton, M. Q. (2002). Qualitative research and evaluation methods (3rd ed.). London: Sage.

Rugh, W. (2004). Arab mass media: Newspapers, radio, and television in Arab politics. Westport, CT: Praeger Publishers.

Sakr, N. (2012) Public service initiatives in Arab media today. In G. F. Lowe, P. Jauert, \& J. Steemers, (Eds.). Regaining the initiative for public service media: RIPE@2011 (pp. 183-198). Göteborg: Nordicom.

Schedler, A. (2009). The new institutionalism in the study of authoritarian regimes. Totalitarianism and Democracy, 6(2), pp. 327-344.

Thussu, D. K. (2004). International communication: Continuity and change. London: Arnold Publishers.

Zaid, B., \& Ibahrine, M. (2011). Mapping digital media: Morocco. The Open Society Foundations. Retrieved from: https://www.opensocietyfoundations.org/reports/mapping-digital-media$\underline{\text { morocco }}$

Zaid, B. (2010). Public service television policy and national development in Morocco: Contents, production, and audiences. Saarbrücken: VDM Verlag. 
